\title{
The ability of coumarin-, flavanon- and flavonol-analogues of flavone acetic acid to stimulate human monocytes
}

\author{
MARIAGNESE BARBERA ${ }^{1,3}$, ANNA CAPUTO ${ }^{1}$, ANTONELLA ZAMPIRON ${ }^{1}$, \\ SILVIA GOBBI ${ }^{2}$, ANGELA RAMPA ${ }^{2}$, ALESSANDRA BISI ${ }^{2}$ and MARIA CARRARA ${ }^{1}$
}

${ }^{1}$ Department of Pharmacology and Anaesthesiology, University of Padova, Largo Meneghetti 2, 35131 Padova; ${ }^{2}$ Department of Pharmaceutical Sciences, University of Bologna, Via Belmeloro 6, 40126 Bologna, Italy; ${ }^{3}$ Department of Biochemistry, University of Cambridge, 80 Tennis Court Road, Cambridge CB2 1GA, UK

Received August 28, 2007; Accepted October 5, 2007

\begin{abstract}
Flavone acetic acid (FAA) is a semi-synthetic flavonoid characterised by potent immune-modulatory and antivascular activity on mice but not in humans. Previously, the synthesis and cytotoxic activity on a human adenocarcinoma cell line of coumarin-, flavanon- and flavonol-derivatives of FAA were described. These analogues were able to induce the reduction of lysosomal neutral red uptake at $5 \times 10^{-5} \mathrm{M}$ concentration and some of them were more effective than FAA. Some of these derivatives were selected to investigate their ability to exert immune-modulation on a human model, by using the most potent analogue that has emerged thus far, 5,6-dimethylxanthenone-4-acetic acid (DMXAA), as a reference compound. We investigated the cytotoxicity of the selected derivatives on two human ovarian adenocarcinoma cell lines and their ability to activate the immune system by inducing lytic properties, TNF- $\alpha$ and nitric oxide in human monocytes. The immune-modulating activity was assessed by treating a cell line of human monocytes (Mono Mac 6, MM6) with FAA-derivatives alone or in association with lipopolysaccharide (LPS). None of the tested molecules showed any significant ability to directly affect tumor cell proliferation, whereas they were able to induce the lytic properties of MM6 cells. In particular, two coumarin derivatives, $a$ and $d$, and the flavonol acetic acid, $l$, showed comparable results to DMXAA. The combination with LPS did not lead to synergistic interactions in the induction of the lytic properties of MM6, but it significantly increased the release of TNF- $\alpha$, especially after $4 \mathrm{~h}$ of treatment. Instead, the maximum release of nitric oxide (NO) was detected after $24 \mathrm{~h}$ of treatment and
\end{abstract}

Correspondence to: Dr Maria Carrara, Department of Pharmacology and Anaesthesiology, University of Padova, Largo Meneghetti 2, 35131 Padova, Italy

E-mail: maria.carrara@unipd.it

Key words: flavone acetic acid, 5,6-dimethylxanthenone-4-acetic acid, TNF- $\alpha$, nitric oxide after exposure to the FAA derivatives alone. Derivative $a$ combined with LPS and analogue $d$ alone were able to induce a higher TNF- $\alpha$ and NO release, respectively, whereas flavonol acetic acid was characterised by a strictly similar activity to DMXAA.

\section{Introduction}

The semi-synthetic molecule flavone-8-acetic acid (FAA, 1; Fig. 1) emerged in a large screening of flavonoids $(1,2)$ for its excellent and peculiar activity against a broad set of transplantable solid murine tumors (such as colon, pancreatic ductal adenocarcinomas, mammary adenocarcinoma, reticulum cell sarcoma and Glasgow's osteosarcoma) normally resistant to many cytotoxic drugs (3). The antitumor profile of FAA involves effects exerted on the immune and vascular systems (4-7). FAA acts on the vascular network not only by altering the blood perfusion, reducing plasma volumes and leading to blood vessel shutdown (8), with a consequent interruption of the tumor blood supply (9), but also by affecting the procoagulant activity of endothelial cells (10). The immunemodulation exerted by FAA involves the natural killer cell activity (5) and the release of several cytokines, among which TNF- $\alpha$ plays the main role (4). Unfortunately, FAA did not exhibit any significant activity in clinical trials (2). In order to obtain an effective molecule on human models, extensive SAR studies have been performed on FAA analogues. These investigations first led to the xanthenone-4acetic acid (11) (XAA, 2; Fig. 1), closely related and significantly more potent than FAA, and then to the synthesis of 5,6dimethyl-xanthenone-4-acetic acid (DMXAA, 3; Fig. 1), the most potent derivative, which turned out to be significantly active on human models and selective on tumor tissue (12). Thus, DMXAA was selected for further investigation and, at present, is under phase II clinical trials as a vascular disrupting agent (13). The DMXAA-mediated immune stimulation results in the induction of the nuclear transcription factor $\mathrm{NF}-\kappa \mathrm{B}$, due to the inactivation of its inhibitory factor, IкB- $\alpha$. This event likely occurs through the allosteric interaction of DMXAA with IKK, a kinase protein which triggers the destruction of IкB- $\alpha$ through its phosphorylating activity (14). Furthermore, a very remarkable enhancement of the TNF- $\alpha$ 
<smiles>O=c1cc(-c2ccccc2)oc2c(CO)cccc12</smiles><smiles></smiles>

Figure 1. Molecular structures of FAA, XAA and DMXAA.

synthesis in human leukocytes (14) and murine splenocytes (15) was pointed out after exposure to the associations of DMXAA and LPS, suggesting that DMXAA requires prior activation of IKK before acting (16).

For some years, our research group has been interested in the synthesis and biological evaluation of FAA analogues (17-21). In a previous study (17), the synthesis and cytotoxic activity on the human tumor cell lines of some FAA derivatives were described. These coumarin-, flavanon- and flavonol-acetic acids were able to induce a statistically significant reduction of lysosomal neutral red uptake at a $5 \times 10^{-5} \mathrm{M}$ concentration. Some compounds were more active than FAA.

In this study, we carefully examined the effects on tumor cell proliferation and immune system activation resulting in treatment with some of these previously studied compounds (Fig. 2), using DMXAA as a reference compound. In particular, we investigated the cytotoxic activity on two human tumor cell lines and their ability to activate the immune system, by evaluating the ability of the derivatives to induce, in human monocytes, lytic properties exerted on a tumor cell line and the release of TNF- $\alpha$ and nitric oxide.

\section{Materials and methods}

Compounds and sample solutions. DMXAA and FAA derivatives were stored in the dark and at room temperature. The samples for experimental use were prepared from stock solutions $\left(10^{-3} \mathrm{M}\right.$, in DMSO and distilled water) and diluted with culture medium. The DMSO concentration in sample solutions was lower than 1\% v/v. LPS (lipopolysaccharide from Escherichia coli serotype 0127; F8, Sigma) was stored at 4 to $8^{\circ} \mathrm{C}$ in the dark and the sample solutions were prepared by diluting a stock solution $(1 \mathrm{mg} / \mathrm{ml}$ in distilled water) with culture medium.

Cell lines. Two human ovarian adenocarcinoma cell lines, 2008 and the cis-DDP-resistant cell line C13*, were used. Both were maintained in RPMI-1640 supplemented with $10 \%$ heat-inactivated FCS, $1 \%$ antibiotics (all products Biochrom KG Seromed) and $200 \mathrm{mM}$ glutamine (Merck). The human monoblastic leukaemia cells Mono Mac 6 (MM6), were supplied by the 'Istituto Nazionale per la Ricerca sul Cancro - Genova' and maintained in the same culture medium and then supplemented with $1 \%$ sodium pyruvate $100 \mathrm{mM}$,<smiles>O=Cc1cccc2cc(-c3ccccc3)c(=O)oc12</smiles>

$a$<smiles>O=Cc1cccc2ccc(=O)oc12</smiles>

$b$<smiles>O=C(O)Cc1cccc2cc(-c3ccc([N+](=O)[O-])cc3)c(=O)oc12</smiles><smiles>O=C(O)c1cccc2cc(-c3ccc(F)cc3)c(=O)oc12</smiles><smiles>O=C(O)c1cccc2cc(-c3ccc(Cl)cc3)c(=O)oc12</smiles><smiles>O=C(O)Cc1cccc2c1OC(c1ccccc1)CC2=O</smiles><smiles>Cc1ccc(C2CC(=O)c3cccc(C)c3O2)cc1</smiles><smiles>O=C(O)c1cccc2c1OC(c1ccc(F)cc1)CC2=O</smiles><smiles>COc1ccc(C2CC(=O)c3cccc(CO)c3O2)cc1</smiles><smiles>O=C(O)Cc1cccc2c(=O)c(O)c(-c3ccccc3)oc12</smiles>

l

Figure 2. Coumarin (a-e)-, flavanon $(f-i)$ - and flavonol $(l)$-acetic acid chemical structures.

$1 \%$ non-essential amino acids and bovine insulin $9 \mu \mathrm{g} / \mathrm{ml}$ (Biochrom KG Seromed).

Cytotoxicity on 2008 and C13* cells. Cells were seeded $\left(8 \times 10^{3}\right.$ cells/well) in 96-well tissue plates (Falcon) and treated with 100, 250 and $500 \mu \mathrm{M}$ DMXAA and FAA derivatives for $24 \mathrm{~h}$. Cell proliferation was evaluated by the tetrazolium salts reduction assay (MTT test).

Cytotoxicity on the Mono Mac 6 cell line. Cells were seeded ( $2 \times 10^{4}$ cells/well) in 96-well tissue plates and exposed to 25 , 50 and $100 \mu \mathrm{M}$ DMXAA and FAA derivatives for $24 \mathrm{~h}$. Cell proliferation was assessed by the tetrazolium salts reduction assay (XTT test).

Stimulation of lytic properties of MM6 cells. MM6 cells were seeded and treated as above in the previous assays. After $24 \mathrm{~h}$ of treatment the media were drawn and the $\mathrm{C} 13^{*}$ cells were plated $\left(2 \times 10^{3}\right.$ cells/well $)$ on the wells containing the treated MM6 cells. The optimal MM6/C13* cell ratio was determined 
Table I. $\mathrm{IC}_{50} \mu \mathrm{M}$ and $95 \%$ confidence limits, after $24 \mathrm{~h}$ of treatment with 100, 250 or $500 \mu \mathrm{M}$ DMXAA or FAA-derivatives.

\begin{tabular}{|c|c|c|c|c|c|}
\hline Cell line & DMXAA & $a$ & $d$ & $f$ & $l$ \\
\hline \multirow[t]{2}{*}{2008} & 448.1 & 1196.7 & & & 2514.7 \\
\hline & $(395.9-507.3)$ & $(872.9-1641.1)$ & & & $(1586.2-3686.8)$ \\
\hline \multirow[t]{2}{*}{ C13* } & 641.8 & & 1616.3 & 740.6 & \\
\hline & $(511.1-805.7)$ & & (999.6-2613.5) & $(589.7-930.2)$ & \\
\hline
\end{tabular}

in previous experiments (results not reported). Cells were cocultured for $24 \mathrm{~h}$ and then the viability of $\mathrm{C} 13^{*}$ was assessed by the XTT test. As a control, samples containing non-treated MM6 and C13* cells and C13* co-cultured with non-treated MM6 were seeded. The percentages of the specific growth of C13* cells were calculated as follows:

$$
\text { OD (treated MM6+C13*) - OD (MM6) }
$$

\section{OD $\left(\mathrm{C} 13^{*}\right)$}

The same assay was also performed by treating MM6 with the same doses of DMXAA or the compounds $a, d$ and $l$, combined with LPS $10 \mathrm{ng} / \mathrm{ml}$.

MTT test. MTT (Sigma) solution (20 $\mu 1$ of which $5 \mathrm{mg} / \mathrm{ml}$ was in PBS) were added to each well and the plates were incubated for $4 \mathrm{~h}$ at $37^{\circ} \mathrm{C}$. Then the media were discarded and the dark blue crystals were dissolved in DMSO (150 $\mu \mathrm{l} /$ well). The absorbance was measured on a micro-culture plate reader (Titertek Multiscan) using 570 and $630 \mathrm{~nm}$ as a test and reference wavelength, respectively.

XTT test. A commercially available kit (Cell proliferation kit II-XTT, Roche) was used to obtain an XTT solution, according to the manufacturer's instructions. XTT (75 $\mu 1)$ was added to each well and the plates were incubated at $37^{\circ} \mathrm{C}$. After $2 \mathrm{~h}$, absorbance was directly measured on a micro-culture plate reader using 450 and $630 \mathrm{~nm}$ as a test and reference wavelength, respectively.

Stimulation of TNF- $\alpha$ release. MM6 cells were treated with DMXAA or the compounds $a, d$ and $l$, with or without LPS at the same concentration used for the MM6-mediated cytotoxicity assays. After 4 or $24 \mathrm{~h}$ incubation, culture media were collected and stored at $-80^{\circ} \mathrm{C}$. A commercially available ELISA kit was used to measure the concentration of TNF- $\alpha$ (Human TNF- $\alpha$ Instant ELISA, Biosource) according to the manufacturer's instructions. The results were normalised according to the protein content of each sample.

Nitric oxide release by 'Griess' reaction. The nitrite/nitrate concentration, a reliable indicator of nitroxide production and release, was evaluated by the photometric 'Griess' reaction, in the same culture media tested for the TNF- $\alpha$ release assay. The samples were previously treated as described by Miranda et al (22), in order to reduce all the nitrate ions to nitrite. Then, $500 \mu 1$ of each sample was mixed with $250 \mu 1$ of Griess A (1\% sulphanilamide in 5\% phosphoric acid) and Griess B $(0.1 \%$ naphtylethylenediamine dihydrochloride in distilled water) reagents (all from Sigma) and the absorbance was measured at $543 \mathrm{~nm}$. The results were normalised according to the protein content of each sample.

Bradford protein assay. The evaluation of the content of proteins in the samples treated for the TNF- $\alpha$ and nitrite assays was carried out according to the Bradford method (23). After treatment of the TNF- $\alpha$ and nitrite assays, the MM6 cells were washed and centrifuged 3 times with ice-cold PBS and then incubated on ice for $30 \mathrm{~min}$ with $0.5 \mathrm{ml}$ lysis buffer (50 mM Tris $\mathrm{HCl}, 1 \mathrm{mM}$ DTT, $1 \mathrm{mM} \mathrm{Na}{ }_{2}$ EDTA and 1\% v/v Triton X-100). The lysates were then centrifuged for $15 \mathrm{~min}$ at $4^{\circ} \mathrm{C}$ and 15,000 rpm and the supernatants were stored at $-80^{\circ} \mathrm{C}$. The lysates were then diluted 15 -fold and mixed with the Bio-Rad protein assay dye (Bio-Rad) according to the manufacturer's instructions. After 10-15 min of incubation in the dark absorbance at $595 \mathrm{~nm}$ wavelength was measured using the 15 -fold diluted lysis buffer as a background.

Statistical analysis. At least three different experiments were performed in triplicate for each drug dose. The results were statistically analysed by the Student's t-test. The $\mathrm{IC}_{50} \mathrm{~s}$, the confidence limits $(95 \%)$ and the potency ratios between DMXAA and each analogue were estimated using the Litchfield and Wilcoxon method.

\section{Results}

Cytotoxicity on 2008, C13* and Mono Mac 6 cell lines. On both of the ovarian adenocarcinoma cell lines, 2008 and C13*, DMXAA showed a statistically significant cytotoxic activity only for the highest dose used $(500 \mu \mathrm{M})$. None of the FAA analogues were able to induce inhibition of cell growth comparable to that obtained with the reference compound (Fig. 3). Derivatives $a$ and $l$, on 2008 cells and analogues $d$ and $f$, on $\mathrm{C}_{13}{ }^{*}$, were the most effective, even though their $\mathrm{IC}_{50}$ was significantly higher than those obtained with DMXAA [2008: $\mathrm{IC}_{50}=448.1(395.9-507.3) \mu \mathrm{M}, \mathrm{C} 13^{*}: \mathrm{IC}_{50}=641.8$ (511.1-805.7) $\mu \mathrm{M}]$ (Table I).

Of the tested doses, neither DMXAA nor any FAA analogue was significantly cytotoxic towards the Mono Mac 6 (MM6) cells (data not shown).

Stimulation of the lytic properties of MM6 cells. The hostmediated antitumor effects induced in vitro by DMXAA and FAA analogues were investigated by measuring their ability to stimulate MM6 cells into exerting a cytotoxic action on $\mathrm{C} 13^{*}$ tumor cells 

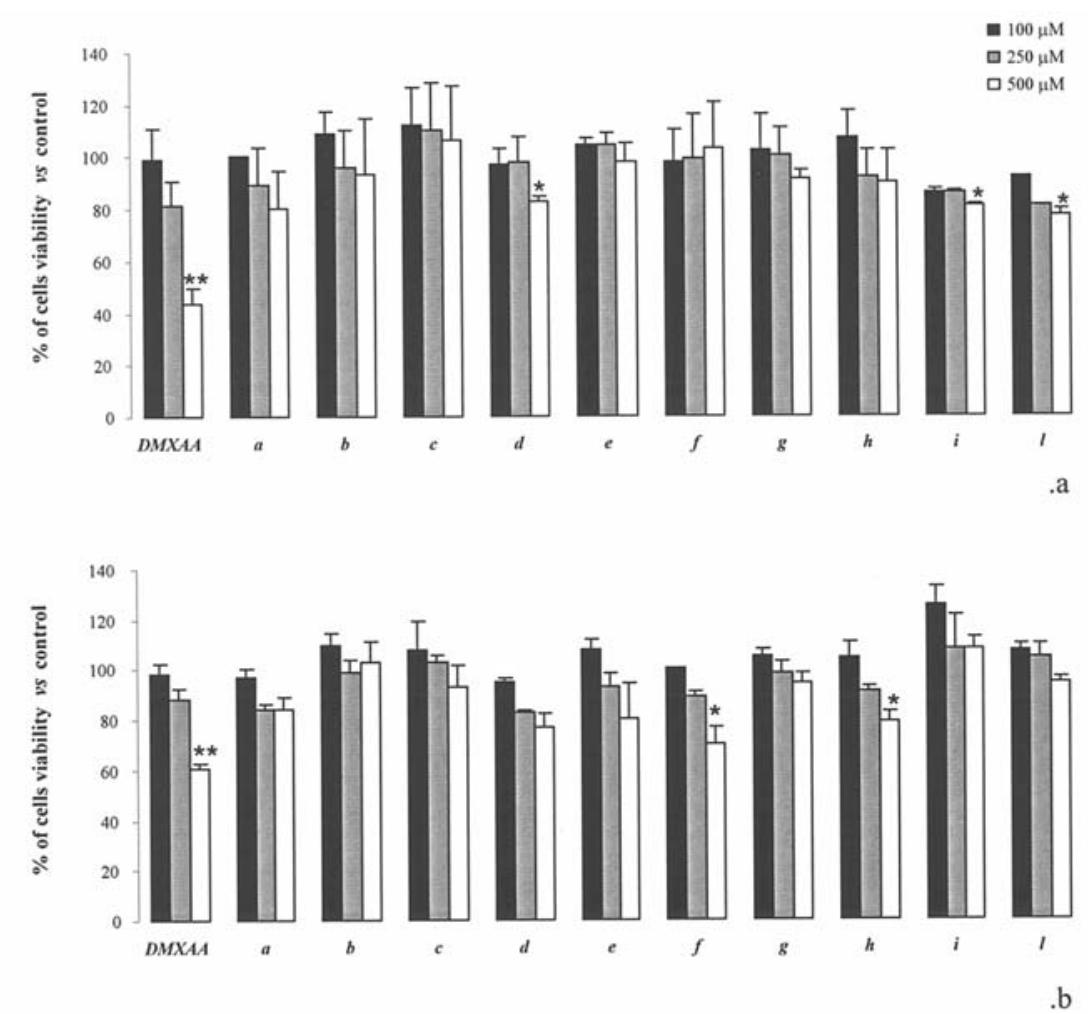

Figure 3. Percentage with respect to the control of the tetrazolium salts reduction (MTT) as an index of the viability of the 2008 (a) and C13* (b) cells, after $24 \mathrm{~h}$ of treatment with 100,250 or $500 \mu \mathrm{M}$ DMXAA or FAA derivatives; ${ }^{*} \mathrm{p}<0.05,{ }^{* *} \mathrm{p}<0.01$.

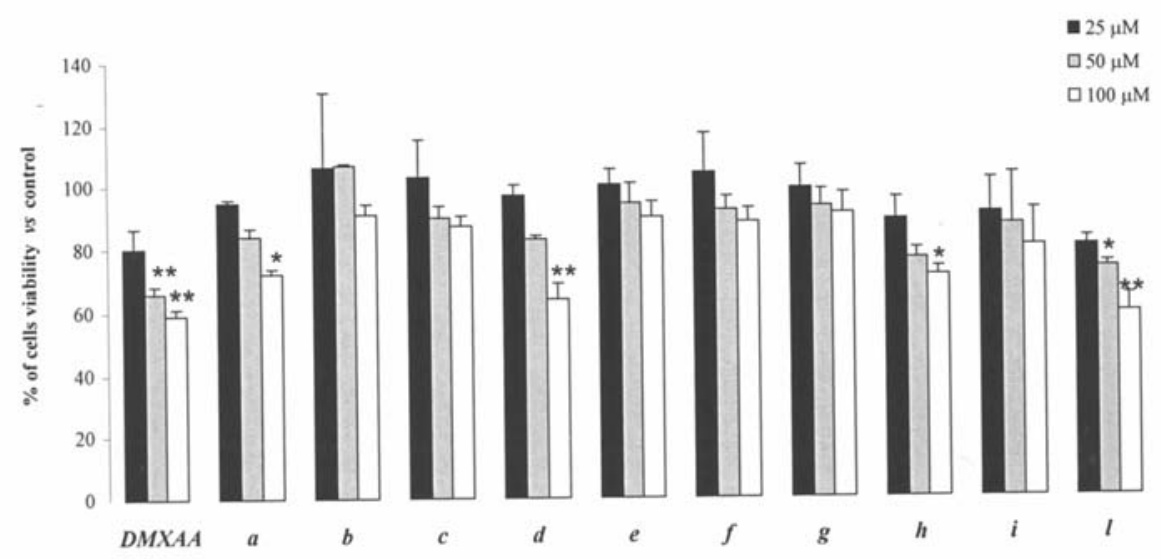

Figure 4. Percentage with respect to the control of the tetrazolium salts reduction (MTT) as an index of the viability of the C13* cells, after $24 \mathrm{~h}$ of co-culture with MM6 cells pre-treated for $24 \mathrm{~h}$ with 100,250 or $500 \mu \mathrm{M}$ DMXAA or FAA derivatives; ${ }^{*} \mathrm{p}<0.05,{ }^{* *} \mathrm{p}<0.01$.

DMXAA showed a remarkable ability to stimulate lytic properties of MM6 (Fig. 4) reducing C13* proliferation in a dose-dependent manner, with an $\mathrm{IC}_{50}$ value $<4$ times than that obtained in cytotoxic assays $\left[\mathrm{IC}_{50}=152.3(106.4-210.0) \mu \mathrm{M}\right.$ versus $\mathrm{IC}_{50}=641.8(511.1-805.7) \mu \mathrm{M}$ ] (Table II). FAAderivatives also generally increased their ability to inhibit C13* growth in comparison to the previous evaluation. In particular, analogues $a, d, h$ and $l$ exerted a statistically significant stimulation of MM6 cell antitumor activity at the highest dose used (100 $\mu \mathrm{M}$, Fig. 4). The most effective compounds, $a, d$ and $l$, showed similar activities and $\mathrm{IC}_{50}$ values to the reference compound: 203.0 (141.7-290.7),
131.7 (102.5-169.3) and 177.1 (123.7-253.5) $\mu \mathrm{M}$, respectively (Table II).

When the same protocol was performed by treating the cells with the LPS associations, the results obtained showed not only that DMXAA and the three tested derivatives did not improve their ability to stimulate MM6 lytic properties, but also that they were less effective than when they were used alone (Fig. 5). Notably, the association with LPS led to $\mathrm{IC}_{50}$ values 1.5- (DMXAA) and 2-fold ( $a, d$ and $l$ ) higher than those obtained in the previous experiment (Table IV). Compound $d$ showed an $\mathrm{IC}_{50}$ value totally comparable to that obtained with DMXAA (Table III). 
Table II. $\mathrm{IC}_{50} \mu \mathrm{M}, 95 \%$ confidence limits and power ratios versus DMXAA and the direct cytotoxicity assays, after $24 \mathrm{~h}$ of coculture of the $\mathrm{C} 13^{*}$ cells with MM6 cells pre-treated with DMXAA or FAA derivatives (100, 250 or $\left.500 \mu \mathrm{M}\right)$.

\begin{tabular}{|c|c|c|c|c|c|c|c|c|c|c|c|}
\hline & DMXAA & $a$ & $b$ & $c$ & $d$ & $e$ & $f$ & $g$ & $h$ & $i$ & $l$ \\
\hline $\mathrm{IC}_{50}$ & $\begin{array}{c}152.3 \\
(106.4-210.0)\end{array}$ & $\begin{array}{c}203.0 \\
(141.7-290.7)\end{array}$ & $\begin{array}{l}- \\
-\end{array}$ & $\begin{array}{l}- \\
-\end{array}$ & $\begin{array}{c}131.7 \\
(102.5-169.3)\end{array}$ & $\begin{array}{l}- \\
-\end{array}$ & - & $\begin{array}{l}- \\
-\end{array}$ & $\begin{array}{c}275.1 \\
(184.2-410.7)\end{array}$ & $\begin{array}{c}1067.5 \\
(497.0-2293)\end{array}$ & $\begin{array}{c}177.1 \\
(123.7-253.5)\end{array}$ \\
\hline $\begin{array}{l}\text { P.R. vs } \\
\text { DMXAA }\end{array}$ & 1.0 & 0.7 & - & - & 1.2 & - & - & - & 0.6 & 0.1 & 0.9 \\
\hline $\begin{array}{l}\text { P.R. vs } \\
\text { Cytotoxicity }\end{array}$ & 4.2 & - & - & - & 12.3 & - & - & - & - & - & - \\
\hline
\end{tabular}

Table III. $\mathrm{IC}_{50} \mu \mathrm{M}, 95 \%$ confidence limits and power ratios versus DMXAA after $24 \mathrm{~h}$ of co-culture of the C13* cells with MM6 cells pre-treated with DMXAA or FAA derivatives $(100,250$ or $500 \mu \mathrm{M})$ associated with $10 \mathrm{ng} / \mathrm{ml}$ LPS.

\begin{tabular}{lcc}
\hline & $\mathrm{IC}_{50} \mu \mathrm{M}$ & P.R. vs DMXAA \\
\hline DMXAA & 220.7 & 1.0 \\
& $(144.3-337.6)$ & \\
$a$ & 350.0 & 0.6 \\
& $(218.6-563.4)$ & \\
$d$ & 211.9 & 1.0 \\
& $(154.0-291.7)$ & \\
& 398.8 & 0.6 \\
\hline
\end{tabular}

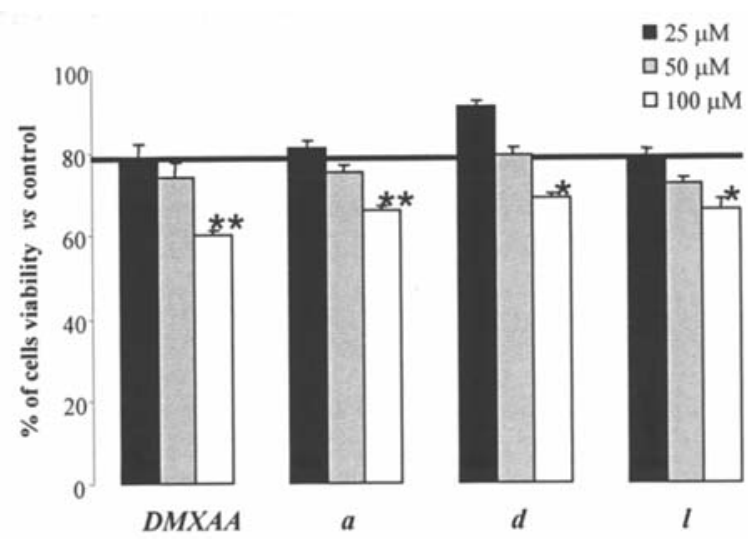

Figure 5. Percentage with respect to the control of the tetrazolium salts reduction (MTT) as an index of the viability of the $\mathrm{C} 13^{*}$ cells, after $24 \mathrm{~h}$ of co-culture with MM6 cells pre-treated for $24 \mathrm{~h}$ with 100,250 or $500 \mu \mathrm{M}$ DMXAA or FAA derivatives associated with $10 \mathrm{ng} / \mathrm{ml}$ LPS. Black line: C13 co-cultured with MM6 treated only with $10 \mathrm{ng} / \mathrm{ml} \mathrm{LPS}$; ${ }^{*} \mathrm{p}<0.05,{ }^{* *} \mathrm{p}<0.01$.

Stimulation of TNF- $\alpha$ release. The release of TNF- $\alpha$ by MM6 was measured after a 4- or 24-h exposure to DMXAA or the compounds $a, d$ and $l$, with or without LPS.

When used alone, the exposure time was the main factor affecting the release of the cytokine. After $4 \mathrm{~h}$ of treatment, derivatives $d$ and $l$ stimulated a remarkable TNF- $\alpha$ release. In particular, the cells exposed to compound $d$ released TNF- $\alpha$ levels significantly higher not only in comparison to the control cells, but also to that exposed to the DMXAA (Fig. 6a). A remarkable TNF- $\alpha$ release was also obtained by treating cells with derivative $l$ at $25 \mu \mathrm{M}$. When the exposure time was extended to $24 \mathrm{~h}$, the DMXAA and FAA analogues completely lost their stimulating ability. Notably, the measured levels of TNF- $\alpha$ were comparable or decreased in compared to the control (Fig. 6b).

When MM6 cells were treated with LPS associations the time reliance of the TNF- $\alpha$ release was confirmed and then increased. In general, after $4 \mathrm{~h}$ of exposure all the tested associations were able to strongly induce $\mathrm{TNF}-\alpha$ production and the cytokine levels were significantly higher than those obtained with either the DMXAA or FAA derivatives alone (Fig. 6c). The result obtained after $4 \mathrm{~h}$ of exposure to LPS association with 25 and $50 \mu \mathrm{M} a$ was noteworthy, as it showed a significant synergistic interaction with the bacterial endotoxin. After $24 \mathrm{~h}$ of treatment, none of the associations led to significant results in comparison to those obtained for the shorter exposure time. Under these experimental conditions, the production of TNF- $\alpha$ was in any case significantly lower than that obtained with LPS alone, suggesting antagonistic interactions (Fig. 6d).

Nitric oxide release by 'Griess' reaction. The nitric oxide release was evaluated in the same medium as the TNF- $\alpha$ assay, by using the nitrite 'Griess reaction' as a reliable indicator of radical release.

Moreover, the time of exposure affected the obtained results but in an inverse manner in compared to the TNF- $\alpha$ release assays. When the MM6 cells were treated with compounds alone, a considerable nitric oxide induction was obtained only after $24 \mathrm{~h}$ of exposure. After $4 \mathrm{~h}$ of treatment not only none of the tested compounds was able to stimulate nitric oxide production, but they also seemed to inhibit its production if compared to the control (Fig. 7a). Instead, following the $24 \mathrm{~h}$ of exposure all the tested compounds powerfully stimulated nitric oxide production (Fig. 7b). In particular, the most remarkable results were obtained with the derivative $d$, which led to a significant nitric oxide release that, in comparison to the control, was about $800 \%$ at $25 \mu \mathrm{M}$ and $500 \%$ at both 50 and $100 \mu \mathrm{M}$. Under these experimental conditions, DMXAA increased the radical release only at $25 \mu \mathrm{M}$. 
Table IV. Summary of the $\mathrm{IC}_{50}, 95 \%$ confidence limits and power ratios of the $\mathrm{IC}_{50} \mathrm{~s}$ after $24 \mathrm{~h}$ of co-culture of the $\mathrm{C} 13^{*}-$ MM6 cells pre-treated with DMXAA or FAA derivatives $(100,250$ or $500 \mu \mathrm{M})$ associated with LPS (10 ng/ml) versus previous experiments.

\begin{tabular}{|c|c|c|c|c|c|}
\hline Compounds & $\begin{array}{l}\mathrm{IC}_{50} \mu \mathrm{M} \\
\text { Cytotoxicity } \\
\text { on } \mathrm{C} 13^{*}\end{array}$ & $\begin{array}{c}\mathrm{IC}_{50} \mu \mathrm{M} \\
\text { Mediated by } \\
\text { Mono Mac } 6\end{array}$ & $\begin{array}{c}\mathrm{IC}_{50} \mu \mathrm{M} \\
\text { Association } \\
\text { LPS }\end{array}$ & $\begin{array}{l}\text { P.R. associations LPS } \\
\text { versus } \\
\text { Cytotoxicity on } \mathrm{C} 13^{*}\end{array}$ & $\begin{array}{c}\text { P.R. associations LPS } \\
\text { versus } \\
\text { Mediated by MM6 }\end{array}$ \\
\hline DMXAA & $\begin{array}{c}641.8 \\
(511.1-805.7)\end{array}$ & $\begin{array}{c}152.3 \\
(106.4-210.0)\end{array}$ & $\begin{array}{c}220.7 \\
(144.3-337.6)\end{array}$ & 2.9 & 0.7 \\
\hline$a$ & $\begin{array}{l}- \\
-\end{array}$ & $\begin{array}{c}203.0 \\
(141.7-290.7)\end{array}$ & $\begin{array}{c}350.0 \\
(218.6-563.4)\end{array}$ & - & 0.6 \\
\hline$d$ & $\begin{array}{c}1616.3 \\
(999.6-2613.5)\end{array}$ & $\begin{array}{c}131.7 \\
(102.5-169.3)\end{array}$ & $\begin{array}{c}211.9 \\
(154.0-291.7)\end{array}$ & 7.6 & 0.6 \\
\hline$l$ & $\begin{array}{l}- \\
-\end{array}$ & $\begin{array}{c}177.1 \\
(123.7-253.5)\end{array}$ & $\begin{array}{c}398.8 \\
(225.6-704.9)\end{array}$ & - & 0.4 \\
\hline
\end{tabular}
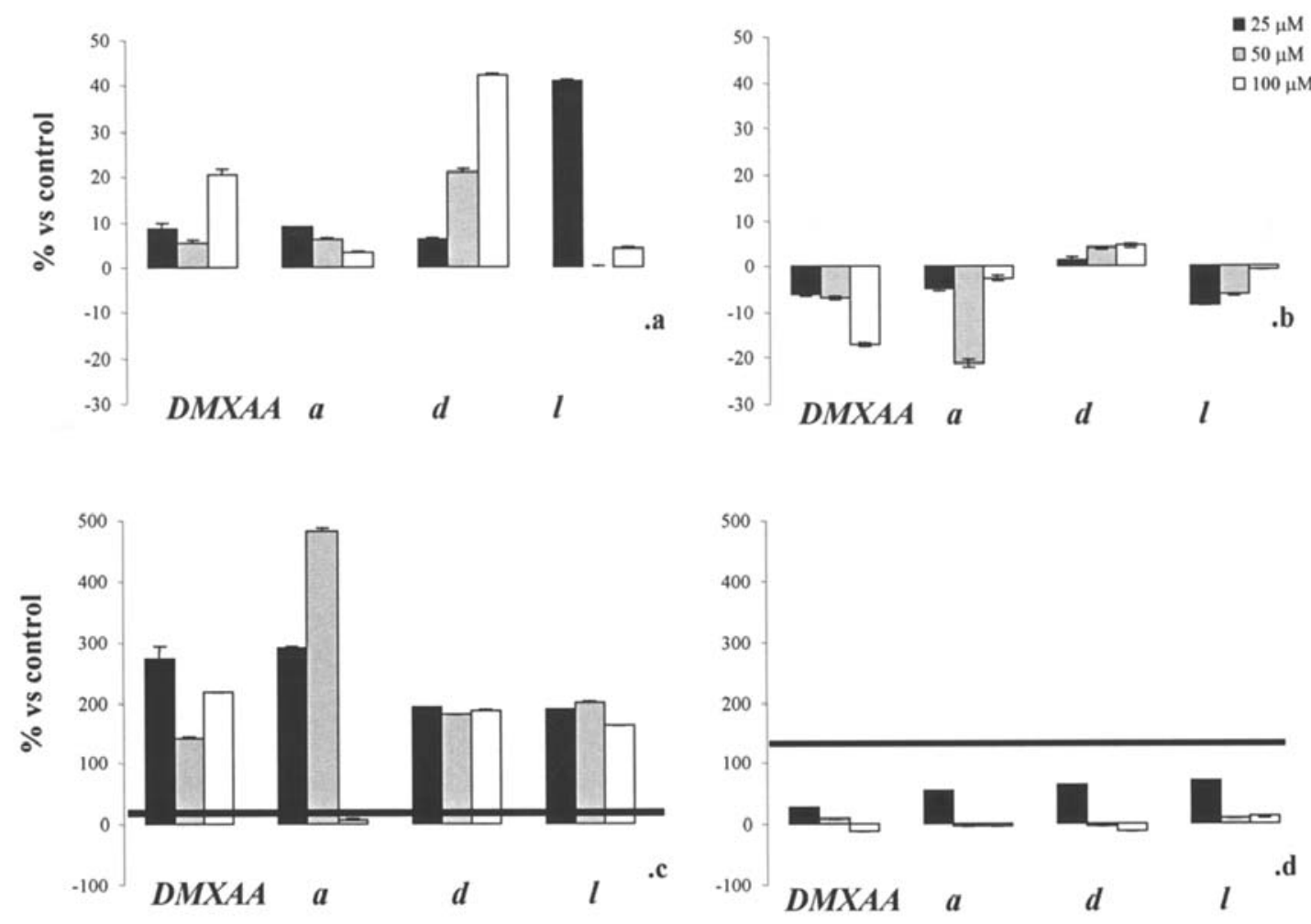

Figure 6. TNF- $\alpha$ (\% vs control) in MM6 supernatants after 5 (a) or 24 h (b) treatment with 25,50 or $100 \mu$ M DMXAA or derivatives $a, d$ or $l$ alone, or associated with $10 \mathrm{ng} / \mathrm{ml}$ LPS for 4 (.c) or $24 \mathrm{~h}$ (.d). Black lines: TNF- $\alpha$ in MM6 cells treated with $10 \mathrm{ng} / \mathrm{ml}$ LPS alone.

Similar results were obtained when the nitric oxide release was assessed on the MM6 cell media after $4 \mathrm{~h}$ of exposure to the derivatives combined with LPS. Neither the DMXAA nor any FAA analogue were able to synergise with the bacterial endotoxin to stimulate the nitric oxide release. Furthermore, all the associations led to a significant decrease both in comparison to the control and to that obtained with the LPS alone (Fig. 7c).
When exposure time was extended to $24 \mathrm{~h}$, the LPS completely lost any ability to stimulate the nitric oxide release, which was quite similar to that obtained with the non-treated cells, while the association with $50 \mu \mathrm{M}$ compound $l$ led to a significant increase of the nitric oxide production both in compared to the derivative $l$ alone and to the LPS alone (Fig. 7d). A strongly antagonistic interaction was obtained with the association LPS-compound $d$, which completely lost 

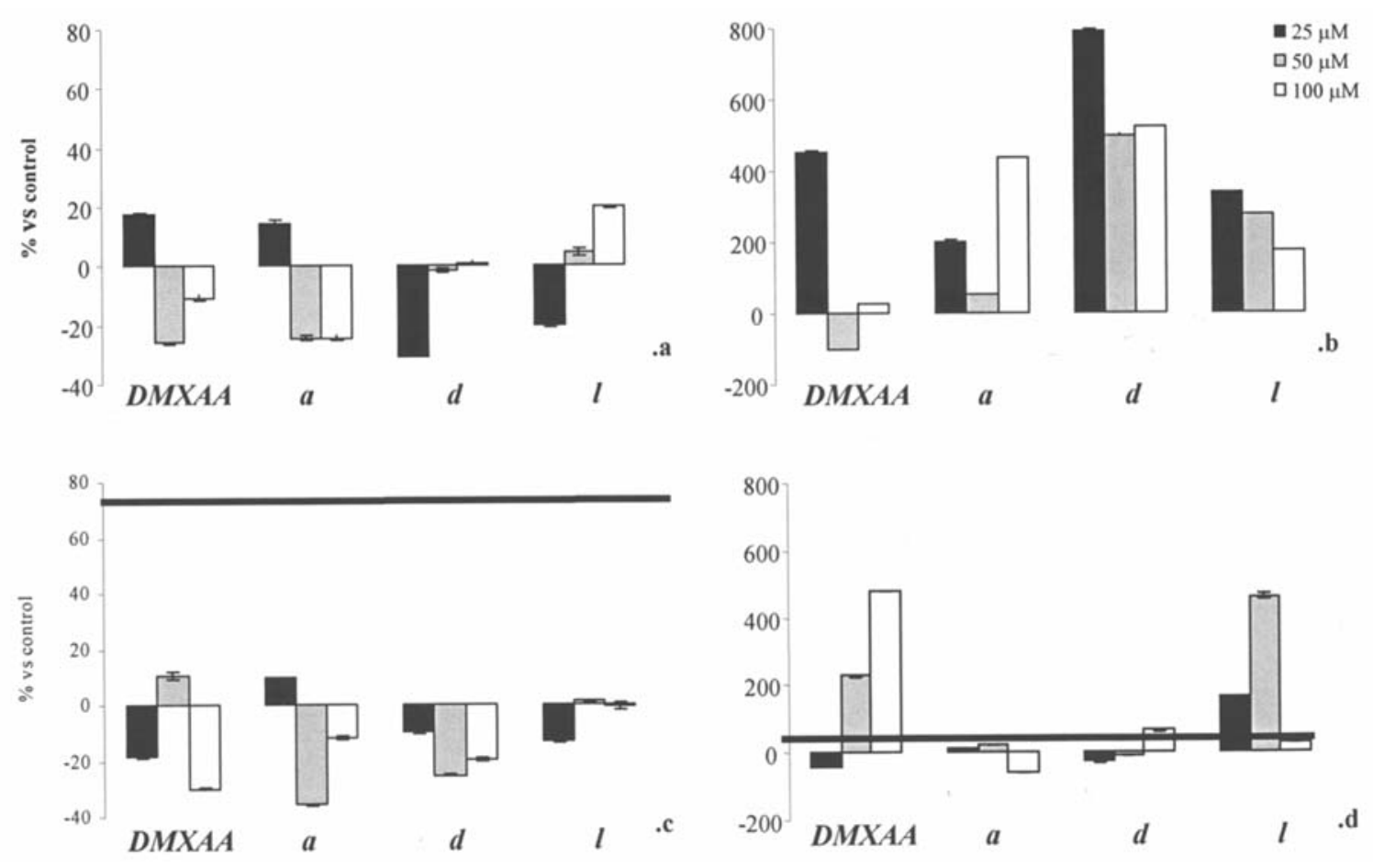

Figure 7. Nitrites (\% vs control) in MM6 supernatants after 5 (a) or 24 h (b) treatment with 25,50 or $100 \mu$ M DMXAA or derivatives $a, d$ or $l$ alone, or associated with $10 \mathrm{ng} / \mathrm{ml}$ LPS for 4 (c) or $24 \mathrm{~h}$ (d). Black lines: nitrite in the MM6 cells treated with $10 \mathrm{ng} / \mathrm{ml} \mathrm{LPS}$ alone.

its ability to stimulate the release of nitric oxide in comparison to when it was used alone. A synergistic increase of radical production was obtained with the association LPS-DMXAA, which was about 230 and $500 \%$ at 25 and $100 \mu \mathrm{M}$, respectively (Fig. 7d).

\section{Discussion}

The interest in studies concerning FAA-derivatives, their synthesis and their biological action is based on the evidence that these molecules are able to exert peculiar antitumor effects involving the immune system and the tumor vascular network. Although FAA failed the clinical trials (24), the potential effectiveness of this approach was confirmed by DMXAA $(3,25-27)$, the most potent FAA and XAA derivative obtained up to now, currently in phase II clinical trials.

The significant activity on human models showed by DMXAA and its selectivity on tumor tissue, resulted first in in vitro (28-30) and then in vivo $(16,25,31,32)$ studies, making this molecule one of the most noteworthy vascular disrupting agents currently in clinical trials. Although DMXAA acts as a powerful antivascular agent in both mice and human tumors, the only evidence of moderate antitumor activity has been obtained in clinical trials, in comparison to the pre-clinical studies $(13,33)$. For that reason further investigation on FAA and XAA derivatives may lead to the detection of more notable molecules.

The cytotoxic activity of some coumarin-, flavanon- and flavonol-FAA derivatives on a colon cancer cell line was the subject of our previous studies (17). In this study, by using DMXAA as a reference, we carefully examined the ability of some of these previously-studied derivatives to exert, in vitro, an immune-modulating activity leading to an indirect antiproliferative action on human tumor cells by the induction of physiological factors involved in the immune response.

All the compounds were tested for cytotoxicity towards the two tumor cell lines, 2008 and $\mathrm{C}^{3} 3^{*}$, arising from a human ovarian adenocarcinoma. The $\mathrm{C} 13^{*}$ cells showed a reduced cell membrane permeability to passive diffusion (34) and mitochondrial membrane functionality $(35,36)$. On both cell lines, FAA derivatives revealed a very low ability to reduce cell proliferation. In fact, cytotoxic effects were obtained only with few derivatives and only at the maximum-tested dose. Few $\mathrm{IC}_{50}$ values could be calculated (for analogues $a$ and $l$ on 2008 and for analogues $d$ and $f$ on $C 13^{*}$ ) and they were even higher than that of DMXAA, taken as a reference for all the evaluations. One of the interesting characteristics first shown by FAA and then by DMXAA was their marginal ability to directly affect the cell proliferation and the results obtained suggest and confirm that these FAA derivatives are not characterised by any remarkable cytotoxic property.

The antitumor effects shown by both FAA and DMXAA seem to involve the immune system by different pathways, including an increase in macrophage-mediated cytotoxicity (4), stimulation of the activity of NK cells (5) and the induction of different cytokines $(37,38)$. Thus, the main key to clarifying the biological meaning of the structural changes brought in by the FAA molecule was the evaluation of host-mediated effects of the synthesized compounds, in terms of their ability to exert, in vitro, an immune-modulating activity leading to an indirect antiproliferative action on human tumor cells by induction of physiological factors involved in the immune response. For this reason we investigated the immune system activation by evaluating the ability of these derivatives to induce, in human monocytes (MM6), lytic properties exerted on a tumor cell line, and TNF- $\alpha$ and nitric oxide release. The 
ability to induce lytic properties in MM6 cells was evaluated as cytotoxicity, induced on $\mathrm{C}_{13}{ }^{*}$ cells co-cultivated with MM6 and pre-treated with the new compounds. MM6, a human monoblastic leukaemia, is a mature macrophage-like cell line that expresses phenotypic and functional properties of mature monocytes (39).

A remarkable increase in antiproliferative activity, compared to the direct cytotoxicity, was observed for both DMXAA and the ten FAA derivatives. The reference compound showed an $\mathrm{IC}_{50}<4$ times than that obtained in the cytotoxicity assay. Among the coumarin-derivatives, $a$ and $d$ showed a significantly mediated cytotoxicity. In particular, a 12-fold enhancement was obtained with the analogue $d$. The substitution of the flavonic core with a flavanonic one did not lead to the molecules being able to stimulate MM6 more than both DMXAA and the other analogues. The two compounds $h$ and $i$ were able to stimulate MM6, but their $\mathrm{IC}_{50}$ values were significantly higher than that obtained with the reference compound, while the flavonol acetic acid $(l)$, which bears a hydroxyl group in position 3 of the FAA core, showed an ability to stimulate MM6 lytic properties similar to that of DMXAA.

Bacterial endotoxin lipopolysaccharide (LPS) is able to induce a powerfully immune stimulation (40) mainly by activating the NF- $\mathrm{KB}$ pathway throught the activation of the membrane receptor CD14 and the induction of NIK (NF-кB inducing kinase), which activates IKK, another kinase, which causes phosphorylation and disruption of I $\mathrm{B}(\mathrm{NF}-\kappa \mathrm{B}$ inhibitor factor) (14). Through this pathway, LPS was able to stimulate the synthesis of many mediators such as TNF- $\alpha$, other cytokines and iNOS. In human cultured leukocytes, DMXAA showed its ability to amplify the immune stimulation effects of LPS with a synergistic interaction (14). Circumstantial evidence points to IKK as a biochemical target for DMXAA provided by the observation that the action of DMXAA on human peripheral blood leukocytes is inhibited by salicylate and the observation that the kinetics of inhibition suggests competition for the same site. Salicylate binds to the $\beta$-subunit of IKK (41). Endotoxin, interleukin-1 and other agents are required to activate IKK and it is likely that DMXAA requires IKK pre-activation before acting. This would explain why DMXAA acts as a co-stimulator rather than an inducer of the TNF- $\alpha$ synthesis and why it can have selective effects on tumor tissue (16). For this reason the hypothesis of the ability of LPS to increase the host-mediated cytotoxicity of DMXAA and selected derivatives, inducing TNF- $\alpha$ and nitric oxide synthesis, was considered. Then, the same protocol reported above was performed in association with LPS.

LPS was able to modify the ability of the FAA derivatives to stimulate the MM6 lytic action, but this influence was negative. The results obtained showed that not only did DMXAA and the three tested derivatives not improve their ability to stimulate MM6 lytic properties, but also that they were less effective in comparison to when they were used alone. In particular, the association with LPS led to $\mathrm{IC}_{50}$ values 1.5- (DMXAA) and 2-fold ( $a, d$ and $l$ ) higher than those obtained in the previous experiment.

The evaluation of TNF- $\alpha$ released by MM6 pre-treated with DMXAA and selected derivatives, alone or associated with LPS, could be a useful indicator of the activity of this class of agents (42). When DMXAA and the selected derivatives were used alone, the exposure time seemed to play an important role. After $4 \mathrm{~h}$ of treatment with DMXAA, $100 \mu \mathrm{M}$ compound $d$ and $25 \mu \mathrm{M} l$, a remarkable release of TNF- $\alpha$ was obtained. A different trend was shown when the exposure time was extended to $24 \mathrm{~h}$. In this case, a remarkable loss of ability to affect the release of TNF- $\alpha$, in comparison either to the result obtained with $4 \mathrm{~h}$ of exposure or to the control, was detected.

Moreover, when the MM6 cells were treated with DMXAA or selected FAA derivatives associated with LPS, the exposure time played a main role in affecting the cytokine release. When the cells were treated for the shortest time a synergistic effect was obtained, but this ability was completely lost when the exposure time was extended to $24 \mathrm{~h}$.

The most significant MM6 stimulation to TNF- $\alpha$ release was obtained using short time exposure and LPS association.

The release of nitric oxide may contribute to the antivascular action of DMXAA. Nitric oxide, although potentially protective against antivascular effects by relaxing arterioles, also increases vascular permeability in tumors by directly affecting endothelial cells (16). Experiments using tumors grown in vitro demonstrated that the pharmacological inhibition of the nitric oxide synthesis reduced the antitumor activity of DMXAA which strongly implicates nitric oxide synthesis in the antitumor action of DMXAA (16).

As with the TNF- $\alpha$ assay, time played a significant role in the release of nitric oxide, but in this case the most interesting results were obtained after $24 \mathrm{~h}$ of treatment. When the cells were treated to the shortest time point none of the tested compounds was able to induce a powerfully nitric oxide release, whereas when the exposure time was extended to $24 \mathrm{~h}$ each compound was able to induce a powerful release compared to the control. In particular, when used alone, compound $d$ was able to induce a powerfully nitric oxide release, 790,500 and $525 \%$ higher to that induced by the control at 25, 50 and $100 \mu \mathrm{M}$, respectively. Under these experimental conditions, DMXAA substantially modified radical production only at $25 \mu \mathrm{M}$.

The ability of DMXAA and the new FAA derivatives to stimulate MM6 nitric oxide production was not affected by the combinations with LPS. Of note is that after $24 \mathrm{~h}$ of exposure, compound $d$ completely lost its activity, whereas compound $l, 25$ and $50 \mu \mathrm{M}$ and DMXAA, 50 and $100 \mu \mathrm{M}$, led to a significant increase of the radical production both in comparison to the compounds alone and to the LPS alone. Thus the nitric oxide release was delayed in compared to the TNF- $\alpha$, probably because the production of the radical is not directly affected by $N F-\kappa B$ activation, but is a result of the iNOS activation that can be enhanced by previously synthesised TNF- $\alpha$ (43).

In conclusion, the modifications made on the FAA structure led to completely different results. The substitution of the flavonic core with a coumarinic structure resulted in the synthesis of two derivatives, $a$ and $d$, which showed an equal ability to stimulate the MM6 lytic properties in comparison to DMXAA. Compound $a$, when associated with LPS and $d$ when used alone, were able to induce a higher TNF- $\alpha$ and nitric oxide release, respectively. The good activity profile of $a$ compared to the inactive compound $b$ 
pointed out the importance of the phenyl nucleus in position 3 of the coumarin core, as well as the positive influence of a fluorine atom on that phenyl compared to other substituents that led to inactive compounds ( $c$ and $e$ ). The substitution of flavonic core with a flavanonic structure (compounds $f, g, h$ and $i$ ) did not lead to any significant improvement of the FAA activity, suggesting a possible main role played by the unsaturated bond between the carbon atoms in positions 2 and 3. The introduction of a hydroxyl group in the molecule of FAA (compound $l$ ) led to the flavonol acetic acid, characterised by a biological profile strictly similar to the reference compound DMXAA.

\section{References}

1. Atassi G, Briet P, Berthelon J and Collonges F: Synthesis and antitumor activity of some 8-substitued-4-oxo-4H-1-benzopyrans. Eur J Med Chem Chim Ther 20: 393-402, 1985.

2. Bibby MC and Double JA: Flavon acetic acid: from laboratory to clinic and back. Anticancer Drugs 4: 3-17, 1993.

3. Plowman J, Narayanan VL, Dyes D, Szarvasi E, Briet P, Yoder OC and Paull DK: Flavone acetic acid: novel agent with preclinical antitumor activity against colon adenocarcinoma 38 in mice. Cancer Treat Rep 70: 631-635, 1986.

4. Ching LM and Baguley BC: Enhancement of in vitro cytotoxicity of mouse peritoneal exudate cells by flavone acetic acid. Eur J Cancer Clin Oncol 24: 1521-1525, 1988.

5. Ching LM and Baguley BC: Induction of natural killer cell activity by the antitumor compound flavone acetic acid. Eur J Cancer Clin Oncol 23: 1047-1050, 1987.

6. Smith GP, Calveley SB, Smith MJ and Baguley BC: Flavone acetic acid induces haemorrhagic necrosis of mouse colon 26 and tumours 38. Eur J Cancer Clin Oncol 23: 1209-1211, 1987.

7. Bibby MC, Double JA, Loadman PM and Duke CV: Reduction of antitumor blood flow by flavon acetic acid: a possible component of therapy. J Natl Cancer Inst 81: 216-220, 1989.

8. Bibby MC, Double JA, Ali SA, Fearon KC, Brennan RA and Tisdale MJ: Characterization of a transplantable adenocarcinoma of the mouse colon producing cachexia in recipient animals. J Natl Cancer Inst 78: 539-546, 1987

9. Zwi JL, Baguley BC and Gavin JB: The use of vascularised spheroids to investigate the action of flavone acetic acid on tumour blood vessels. Br J Cancer 62: 231-237, 1990.

10. Murray JC, Smith KA and Stern DM: Flavone acetic acid potentiates the induction of endothelial procoagulant activity by tumor necrosis factor. Eur J Cancer 27: 765-770, 1991.

11. Rewcastle GW, Atwell GJ, Baguley BC, Calveley SB and Denny WA: Potential antitumor agents, 58. Synthesis and structure-activity relationships of substituted xanthenone-4acetic acids active against the colon 38 tumor in vivo. J Med Chem 32: 793-799, 1989.

12. Baguley BC and Ching LM: Immunomodulatory action of xanthenone anticancer agents. Biodrugs 8: 119-127, 1997.

13. Jameson MB, Thompson PI, Baguley BC, et al: Phase I pharmacokinetic and pharmacodynamic study of 5,6-dimethylxanthenone-4-acetic acid (DMXAA), a novel antivascular agent. Proc Am Soc Clin Oncol 19: 182, 2000.

14. Philpott M, Ching L-M and Baguley B: The antitumor agent 5,6 -dimethylxanthenone-4-acetic acid acts in vitro on human mononuclear cells as a co-stimulator with other inducers of tumor necrosis factor. Eur J Cancer 37: 1930-1937, 2001.

15. Wang LC, Reddy CB, Baguley BC, Kestell P, Sutherland R and Ching LM: Induction of tumor necrosis factor and interferon- $\gamma$ in cultured murine splenocytes by the antivascular agent DMXAA and its metabolites. Biochem Pharmacol 67: 937-945, 2004.

16. Baguley BC and Ching L-M: DMXAA: an antivascular agent with multiple host responses. Int J Radiat Oncol Biol Phys 54: 1503-1511, 2002.

17. Valenti P, Fabbri G, Rampa A, Bisi A, Gobbi S, Da Re P, Carrara M, Sgevano A and Cima L: Synthesis and antitumor activity of some analogues of flavone acetic acid. Anticancer Drug Des 11: 243-252, 1996.

18. Valenti P, Bisi A, Rampa A, Gobbi S, Belluti F, Da Re P, Cima L and Carrara M: Synthesis of flavone-2'-carboxylic acid analogues as potential antitumor agents. Anticancer Drug Des 13: 881-892, 1998.
19. Valenti P, Bisi A, Rampa A, Belluti F, Gobbi S, Zampiron A and Carrara M: Synthesis and biological activity of some rigid analogues of flavone-8-acetic acid. Bioorg Med Chem 8: 239-246, 2000.

20. Gobbi S, Rampa A, Bisi A, Belluti F, Piazzi L, Valenti P, Caputo A, Zampiron A and Carrara M: Synthesis and biological evaluation of 3-alkoxy analogues of flavone-8-acetic acid. J Med Chem 46: 3662-3669, 2003.

21. Carrara M, Zampiron A, Barbera M, Caputo A, Bisi A, Gobbi S, Belluti F, Piazzi L, Rampa A and Valenti P: Mono- or difluorinated analogues of flavone-8-acetic acid: synthesis and in vitro biological activity. Anticancer Res 25: 1179-1185, 2005.

22. Miranda KM, Espey MG and Wink DA: A rapid and simple spectrofotometric method for simultaneous detection of nitrate and nitrite. Nitric Oxide Biol Chemis 5: 62-71, 2001.

23. Bradford MM: A rapid and sensitive method for the quantitation of microgram quantities of protein utilizing the principle of protein dye-binding. Anal Biochem 72: 248-254, 1976.

24. De Forni M, Chabot GG, Gouyette JA, Clink-Alak M and Recondo G: Phase I and pharmacology study of flavone acetic acid administered two or three times weekly without alkalinization. Cancer Chemother Pharmacol 35: 219-224, 1995.

25. Rewcastle G, Atwell G, Li Z, Baguley B and Denny W: Potential antitumor agents. Structure-activity relationship for in vivo colon 38 activity among desubstituted 9-oxo-9Hxanthene-4-acetic acids. J Med Chem 34: 217-222, 1991.

26. Rewcastle G, Atwell G, Palmer B, Boyd P, Baguley B and Denny W: Potential antitumor agents. 62. Synthesis and structure-activity relationship for triciclic compounds relate to the colon tumor active 9-oxo-9H-xanthene-4-acetic acids. J Med Chem 34: 491-496, 1991.

27. Rewcastle G, Atwell G, Baguley B, Boyd P, Thomsen L, Zhuang L and Denny W: Potential antitumor agents. 63 . Structure-activity relationship for side chain analogues of the colon 38 active agents 9-oxo-9H-xanthene-4-acetic acids. J Med Chem 34: 2864-2860, 1991.

28. Futami H, Eader L, Back TT, Gruys E, Young HA, Wiltrout RH and Baguley BC: Cytokine induction and therapeutic synergy with interleukin- 2 against murine renal and colon cancers by xanthenone-4 d derivatives.-acetic acid. J Immunother 12: 247-255, 1992.

29. Laws AL, Matthew AM, Double JA and Bibby MC: Preclinical in vitro and in vivo activity of 5,6-dimethylxanthenone-4-acetic acid. Br J Cancer 71: 1204-1209, 1995.

30. Ching LM, Joseph WR and Baguley BC: Stimulation of macrophage tumouricidal activity by 5,6 -dimethyl-xanthenone4-acetic acid, a potent analogue of the antitumour agent flavone8-acetic acid. Biochem Pharmacol 44: 192-195, 1992.

31. Zwi LJ, Baguley BC, Gavin JB and Wilson WR: The morphological effects of the antitumor agents flavone acetic acid and 5,6-dimethyl xanthenone acetic acid on the colon 38 mouse tumor. Pathology 26: 161-169, 1994.

32. Philpott M, Baguley B and Ching L-M: Induction of tumor necrosis factor-alpha by a single and repeated doses of antitumor agent 5,6-dimethylxanthenone-4-acetic acid. Cancer Chemother Pharmacol 36: 143-148, 1995.

33. Jameson MB, Thompson PI, Baguley BC, Evans BD, Harvey VJ, Porter DJ, McCrystal MR, Small M, Bellenger K, Gumbrell L, Halbert GW and Kestell P: Phase I/II trials committee of cancer research UK: Clinical aspects of a phase I trial of 5,6-dimethylxanthenone-4-acetic acid (DMXAA), a novel antivascular agent. Br J Cancer 88: 1844-1850, 2003.

34. Marverti G and Andrews P: Stimulation of cis-diamminedichloroplatinum (II) accumulation by modulation of passive permeability with genistein: an altereted respomse in accumulation-defective resistant cells. Cancer Res 2: 991-999, 1996.

35. Zinkewich-Peotti K and Andrews PA: Loss of cis-diamminedichloroplatinum (II) resistance in human ovarian carcinoma cells selected for rhodamine 123 resistance. Cancer Res 52: 1902-1906, 1992.

36. Andrews PA and Albright KD: Mithocondrial defects in cisdiamminedichloroplatinum (II)-resistant human ovarian carcinoma cells. Cancer Res 52: 1985-1901, 1992.

37. Baguley BC, Calveley SB, Crowe KK, Fray LM, O'Rourke SA and Smith GP: Comparison of the effects of flavone acetic acid, fostriecin, homoharringtonine and tumor necrosis factor-alpha on colon 38 tumors mice. Eur J Cancer Clin Oncol 25: 263-269, 1989. 
38. Mace KF, Hornung RL, Wiltrout RH and Young HA: Correlation between in vivo induction of cytokine gene expression by flavone acetic acid and strict dose dependency and therapeutic efficacy against murine renal cancer. Cancer Res 50: $1742-1747,1990$.

39. Ziegler-Heitbrock HWL, Thiel E, Fütteree A, Herzog V, Wirtz A and Riethmuller G: Establishment of a human cell line Mono Mac 6 with characteristics of mature monocytes. Int J Cancer 41: 456-461, 1988

40. Yamamoto H, Hanada $\mathrm{K}$ and Nishijima M: Involvement of dyacylglycerol of nuclear factor $\kappa \mathrm{B}$ by CD14-mediated lipopolysaccharide stimulus. Biochem J 325: 223-228, 1997.
41. Yin Y, Yamamoto MJ and Gaynor RB: The anti-inflammatory agents aspirin and salicylate inhibit the activity of I kappa B kinase-beta. Nature 396: 77-80, 1998.

42. Philpott M, Joseph WR, Crosier KE, Baguley BC and Ching LM: Production of tumor necrosis factor-alpha by cultured human peripheral blood leukocytes in response to the antitumor agent 5,6-dimethylxanthenone-4-acetic acid (NSC 640488). Br J Cancer 76: 1586-1591, 1997.

43. Tsai S-H, Lin-Shiau S-Y and Lin J-K: Suppression of nitric oxide synthase and the down-regulation of the activation of NF- $\mathrm{B}$ in macrophages by resveratrol. Br J Pharmacol 126: 673-680, 1999. 